\title{
Relation between lipogranuloma formation and fibrosis, and the origin of brown pigments in lipogranuloma of the canine liver
} Kaori Isobe*, Hiroyuki Nakayama and Koji Uetsuka

\author{
Address: Department of Veterinary Pathology, Graduate School of Agricultural and Life Sciences, University of Tokyo, Japan \\ Email: Kaori Isobe* - born_to_see_you@hotmail.co.jp; Hiroyuki Nakayama - anakaya@mail.ecc.u-tokyo.ac.jp; \\ Koji Uetsuka - akasata@mail.ecc.u-tokyo.ac.jp \\ * Corresponding author
}

Published: 12 May 2008

Comparative Hepatology 2008, 7:5 doi:10.1 186/1476-5926-7-5

This article is available from: http://www.comparative-hepatology.com/content/7/1/5

(c) 2008 Isobe et al; licensee BioMed Central Ltd.

This is an Open Access article distributed under the terms of the Creative Commons Attribution License (http://creativecommons.org/licenses/by/2.0), which permits unrestricted use, distribution, and reproduction in any medium, provided the original work is properly cited.

\begin{abstract}
Background: In a previous study we confirmed that canine hepatic lipogranuloma, defined as lesions consisting of small round cells which contain lipid vacuoles and brown pigments in their cytoplasm, was an assembly of Kupffer cells and/or macrophages, and that the cytoplasmic brown pigments in the lesions were hemosiderin and ceroid. However, the pathogenesis of the lesion remains unclear. Kupffer cells (resident macrophages) play a key role in hepatic fibrogenesis due to the production of cytokines including TGF- $\beta$. In the present study, we have examined 52 canine liver samples (age: newborn - 14 years; 25 males and 27 females) and investigated the correlation between lipogranuloma formation and fibrosis as well as the origin of brown pigments of lipogranulomas.
\end{abstract}

Results: Lipogranulomas were detected histopathologically in 23 (44.2\%) of the 52 liver samples. No significant correlation was found between the density of lipogranulomas and distribution of collagen type I/III in the liver. Pigmentation of lipogranulomas showed significant correlations with that on both hepatocytes and sinusoidal cells, indicating that pigments of lipogranuloma (hemosiderin and ceroid) might be derived from hepatocytes and Kupffer cells.

Conclusion: Lipogranulomas are not a contributing factor in hepatic fibrosis, but might be a potential indicator of the accumulation of iron and lipid inside the liver.

\section{Background}

Lipogranulomas, also termed fatty cysts, are often found in the hepatic parenchyma of dogs $[1,2]$, especially of those with portosystemic shunt (PSS) [3-6], and are defined as lesions consisting of small round cells which contain lipid vacuoles and brown pigments in their cytoplasm, although the amounts of vacuoles and pigments vary among lesions. Besides the canine liver, lipogranulomas are observed in the rat as well as in human livers with cirrhosis [7-10], and are considered to be involved in hepatic cirrhosis in human medicine $[9,10]$. However, in canine cases, the significance of lipogranulomas in the pathogenesis of cirrhosis is still not clear.

Our previous study [11] confirmed that hepatic lipogranuloma consisted of Kupffer cells and/or macrophages, and the cytoplasmic brown pigments were hemosiderin and ceroid, although the pathogenesis of canine lipogranuloma remains unclear. Kupffer cells (resident macrophages) play a key role in hepatic fibrogenesis due to the production of cytokines including transforming growth factor- $\beta$ (TGF- $\beta$ ) [12-14]. TGF- $\beta$, one of the most pro- 
fibrotic cytokines, is necessary and sufficient for the induction and progression of fibrotic lesions, and may serve as the initiating event in the activation of myofibroblasts, which then secrete a large amount of extracellular matrix [15]. We therefore supposed that the component cells of lipogranulomas might have the potential to cause hepatic fibrosis.

Moreover, it is uncertain from where the pigments of canine lipogranuloma are derived. Although it is already demonstrated that hepatocytes are not directly involved in lipogranuloma formation [11], it might be possible that hepatocytes containing pigments are phagocytized by Kupffer cells, which then form a lipogranuloma.

In the present study, we histopathologically examined the correlation between lipogranulomas and fibrosis, and speculated the origin of brown pigments of lipogranulomas.

\section{Results}

\section{Histopathology of the liver}

Histopathological diagnoses of the 52 canine autopsy cases examined in the present study are shown in Table 1. Histopathological changes in the liver were observed in most cases. In cases 8, 19, 28, 34, 36 and 38, tumor metastases to the liver were observed. In case 18 , thrombi were formed in large vessels in the portal area. In case 52, nodular proliferation of well-differentiated hepatocarcinoma was focally observed. In case 41 , cholangiocarcinoma proliferated densely with a tubuliform pattern.

\section{Incidence and density of lipogranulomas}

Among 52 autopsy cases, lipogranulomas were found in the livers of 23 cases $(44.2 \%)$ (Table 1$)$. The density of lipogranulomas was classified into scores 0 to 3: score 0 : 29 cases $(55.8 \%)$; score 1 : 14 cases $(27.0 \%)$; score 2: 6 cases $(11.5 \%)$; and score 3: 3 cases $(5.8 \%)$ of total 52 canine cases. The mean score was $1.5 \pm 0.7$ (mean \pm S.D.).

\section{Fibrosis score}

Fibrosis was graded with scores 0 to 3 (Table 2) according to the amount and distribution of collagen. The mean scores for fibrosis were: collagen type I; $1.6 \pm 1.1$, and type III; $2.3 \pm 0.6$. Neither score was statistically related to that of lipogranuloma density.

\section{Pigmentation score}

Lipogranuloma is defined as an aggregation of cells containing lipid vacuoles and brown pigments in the cytoplasm, as mentioned above. The pigments were positively stained with Berlin blue and Schmorl (Fig. 1a,d). Such pigments were seen also in the cytoplasm of some hepatocytes (Fig. 1b,e) and sinusoidal cells (Fig. 1c,f). The scores of pigmentation are summarized in Table 3 , indi- cating $2.2 \pm 1.1$ (Berlin blue) and $2.2 \pm 0.7$ (Schmorl) of lipogranuloma, $1.3 \pm 0.9$ (Berlin blue) and $2.2 \pm 0.6$ (Schmorl) of hepatocytes, and $2.3 \pm 1.1$ (Berlin blue) and $2.1 \pm 0.8$ (Schmorl) of sinusoidal cells. Regarding the amount of Berlin blue-positive iron pigments in lipogranulomas, hepatocytes and sinusoidal cells, positive correlations were mutually found among them $(\mathrm{P}<0.05)$ (Table $3)$. Schmorl-positive ceroid pigmentation in lipogranulomas was positively correlated both with that on hepatocytes and sinusoidal cells from the results of Schmorl $(\mathrm{P}<$ $0.05)$, although no correlation was observed between pigmentation in hepatocytes and sinusoidal cells (Table 3).

\section{Discussion}

Hepatic lipogranulomas are defined as lesions consisting of small round cells which contain lipid vacuoles and brown pigments in their cytoplasm, although the amounts of vacuoles and pigments vary among lesions. Our previous study [11] confirmed that the lesions consisted of Kupffer cells and/or macrophages, and the cytoplasmic brown pigments are hemosiderin and ceroid.

Macrophages play a very prominent role in fibrotic diseases [15]. Resident and/or infiltrating macrophages play a critical part in initiation of myofibroblast conversion from precursor fibroblasts, fat-storing cells (Ito cells), and endothelial cells [15]. Among them, Kupffer cells (resident macrophages) play a key role in fibrogenesis due to the production of transforming growth factor- $\beta$ (TGF- $\beta$ ) [12-14], hepatocyte growth factor (HGF) [16], tumornecrosis factor- $\alpha$ (TNF- $\alpha$ ) and nitric oxide, which in turn activate fat-storing cells [17-19].

As no significant correlation was found between the density of lipogranulomas and distribution of collagen fibres, lipogranuloma may not be directly involved in fibrogenesis of the liver. Since hepatic fibrosis is a complex process that involves many hepatic cells other than Kupffer cells and/or macrophages, it might be possible that the phagocytes could just trigger initiation of fibrotic events, but could not amplify the fibrotic response which is necessary for hepatic fibrosis.

The abnormal metabolism of iron and lipid may cause the accumulation of hemosiderin and ceroid, respectively. Accumulation of hemosiderin may indicate an increase of red blood cell turnover, and that of ceroid may be a result of increased hepatocyte turnover [2]. Iron and ceroid accumulation is involved in increased oxidative stress with iron-catalyzed production of reactive oxygen species causing oxidative damage to lipids, proteins, and other molecules $[20,21]$. This mechanism may bring about the accumulation of iron and ceroid in hepatocytes, which are then phagocytized by Kupffer cells or macrophages, and subsequently a closely-aggregated "lipogranulomas" are 
Table I: Canine autopsy cases examined.

\begin{tabular}{|c|c|c|c|c|c|}
\hline Case No. & Sex $^{a)}$ & $\mathbf{A g e}^{\mathrm{b})}$ & Breed & Lipogranulomas & Main diagnosis \\
\hline 1 & M & $0 y$ & Labrador Retriever & - & Systemic hyperemia/congestion \\
\hline 2 & $M$ & $0 y$ & Labrador Retriever & - & Systemic hyperemia/congestion \\
\hline 3 & $\mathrm{~F}$ & $7 \mathrm{~m}$ & Mongrel & + & Renal dysplasia \\
\hline 4 & Mc & 3 y $1 \mathrm{~m}$ & Chihuahua & - & Necrotizing meningoencephalitis \\
\hline 5 & $\mathrm{~F}$ & 3 y $5 \mathrm{~m}$ & Shetland Sheepdog & - & Thymoma, Septicemia \\
\hline 6 & $M$ & 3 y $10 \mathrm{~m}$ & Shibainu & - & Severe enteritis, Nephritis \\
\hline 7 & $\mathrm{~F}$ & $4 y$ & Miniature Dachshund & - & Malignant lymphoma \\
\hline 8 & $M$ & $4 y$ & Bernese Mountain Dog & - & Malignant lymphoma \\
\hline 9 & Mc & 4 y $4 \mathrm{~m}$ & American Cocker Spaniel & - & Meningoencephalitis \\
\hline 10 & Fs & 4 y $5 \mathrm{~m}$ & Maltese & + & Necrotizing meningoencephalitis \\
\hline 11 & $M$ & 4 y $6 \mathrm{~m}$ & Miniature Dachshund & - & Thrombocytopenia \\
\hline 12 & Fs & 5 y $2 \mathrm{~m}$ & Miniature Schnauzer & - & Chronic interstitial nephritis \\
\hline 13 & Mc & 5 y $4 \mathrm{~m}$ & Miniature Dachshund & - & Gastroduodenitis \\
\hline 14 & $\mathrm{~F}$ & $6 y$ & Miniature Dachshund & + & Malignant melanoma \\
\hline 15 & $\mathrm{~F}$ & 6 y $2 \mathrm{~m}$ & Shih Tzu & - & hepatic and renal calcinosis \\
\hline 16 & Mc & 6 y $3 \mathrm{~m}$ & Akitainu & - & Peritonitis, Septicemia \\
\hline 17 & $\mathrm{~F}$ & $7 y$ & Labrador Retriever & + & Chronic myelocytic leukemia \\
\hline 18 & M & 7 y $4 \mathrm{~m}$ & English Cocker Spaniel & + & Thrombosis \\
\hline 19 & Mc & 7 y $4 \mathrm{~m}$ & Golden Retriever & - & Malignant lymphoma \\
\hline 20 & $\mathrm{~F}$ & 7 y $9 \mathrm{~m}$ & Shetland Sheepdog & - & Chronic bronchopneumonia \\
\hline 21 & $\mathrm{~F}$ & $8 y 1 \mathrm{~m}$ & Shih Tzu & - & Enteritis, Interstitial nephritis \\
\hline 22 & $\mathrm{~F}$ & 8 y $3 \mathrm{~m}$ & Pug & + & Necrotizing meningoencephalitis \\
\hline 23 & $M$ & $8 \times 9 \mathrm{~m}$ & Yorkshire Terrier & + & Catarrhal pneumonia \\
\hline 24 & Fs & $9 y$ & Golden Retriever & - & Mammary carcinoma \\
\hline 25 & $M$ & $9 y$ & Miniature Pinscher & + & Malignant mesothelioma \\
\hline 26 & $M$ & 9 y $3 \mathrm{~m}$ & Labrador Retriever & + & Malignant lymphoma \\
\hline 27 & $M$ & $9 \times 6 \mathrm{~m}$ & Miniature Schnauzer & + & Hemangiosarcoma \\
\hline 28 & $M$ & 9 y $7 \mathrm{~m}$ & Whippet & - & Malignant histiocytoma \\
\hline 29 & $\mathrm{~F}$ & 9 y $9 \mathrm{~m}$ & Golden Retriever & + & Malignant mesothelioma \\
\hline 30 & $M$ & 9 y $9 \mathrm{~m}$ & Golden Retriever & - & Encephalatrophy \\
\hline 31 & $M$ & $9 \times 9 \mathrm{~m}$ & Welsh Corgi Pembroke & - & Pulmonary calcinosis \\
\hline 32 & $M$ & $10 y$ & German Shepherd Dog & - & Infarction of heart, kidney, lung \\
\hline 33 & $\mathrm{~F}$ & 10 y $4 \mathrm{~m}$ & Shih Tzu & - & Intestinal hemorrhage \\
\hline 34 & $\mathrm{~F}$ & 10 y $7 \mathrm{~m}$ & Welsh Corgi Pembroke & - & Malignant lymphoma \\
\hline 35 & Mc & $10 y 11 \mathrm{~m}$ & Labrador Retriever & + & Acute leukemia \\
\hline 36 & Fs & IIy & Mongrel & - & Fibrosarcoma \\
\hline 37 & $\mathrm{~F}$ & 11 y $3 \mathrm{~m}$ & Shih Tzu & - & Acute lymphocytic leukemia \\
\hline 38 & $\mathrm{~F}$ & 11 y $3 \mathrm{~m}$ & Labrador Retriever & + & Mammary carcinoma \\
\hline 39 & $M$ & 11 y $5 \mathrm{~m}$ & Beagle & - & Malignant lymphoma \\
\hline 40 & $M$ & $1 \mathrm{l}$ y $5 \mathrm{~m}$ & Shetland Sheepdog & - & Malignant histiocytoma \\
\hline 41 & Fs & 11 y $5 \mathrm{~m}$ & Cavalier King Charles Spaniel & - & Uremic pneumonia \\
\hline 42 & $\mathrm{~F}$ & 11 y $10 \mathrm{~m}$ & Miniature Dachshund & + & Cholangiosarcoma \\
\hline 43 & Mc & $12 y$ & Golden Retriever & + & Hemangiosarcoma \\
\hline 44 & $\mathrm{~F}$ & 12 y $5 \mathrm{~m}$ & Shih Tzu & - & Chronic interstitial nephritis \\
\hline 45 & Fs & 12 y $6 \mathrm{~m}$ & Mongrel & + & Malignant lymphoma \\
\hline 46 & $\mathrm{~F}$ & $13 y$ & Miniature Dachshund & + & Fibrinopurulent pneumonia \\
\hline 47 & Fs & $13 y$ & Mongrel & + & Transitinal carcinoma \\
\hline 48 & $\mathrm{~F}$ & 13 y $9 \mathrm{~m}$ & Long Coat Chihuahua & + & Chronic nephritis \\
\hline 49 & $\mathrm{~F}$ & 13 y $9 \mathrm{~m}$ & Miniature Dachshund & + & Malignant lymphoma \\
\hline 50 & $M$ & $14 y$ & Shih Tzu & + & Gastric perforation \\
\hline 51 & Fs & $14 y$ & Labrador Retriever & + & Cardiac calcinosis, Thrombosis \\
\hline 52 & Mc & 14 y 3 m & Italian Greyhound & + & Bronchial adenocarcinoma \\
\hline
\end{tabular}

a) M: male; Mc: male castrated; F: female; Fs: female spayed. b) y: years; m: months.

formed (Fig. 2). In canine PSS cases, on the other hand, increased iron absorption at the duodenum [22] and increased accumulation of ceroid caused by abnormal lipid metabolism in the hepatocytes, might be key factors in forming lipogranulomas (Fig. 2). Since hemosiderin and ceroid are end metabolic products of iron and lipid, respectively, the pigments remain in phagocytes once they are phagocytized [21,23]. 
Table 2: Scoring criteria for distribution of collagen type I/III, and pigmentation in the liver.

\begin{tabular}{|c|c|c|}
\hline Score & Distribution of collagen type I/III & Pigmentation \\
\hline 0 & None & None \\
\hline I & Thin collagen fibers are occasionally observed in the foci of hepatocytic changes and/or periportal area & Light \\
\hline 2 & Distinct collagen fibers are observed in the foci of hepatocytic changes and/or periportal area & Moderate \\
\hline 3 & Thick and distinct collagen fibers are observed in the foci of hepatocytic changes and periportal area & Severe \\
\hline
\end{tabular}

As demonstrated in our previous study [11], hepatocytes are not mainly involved in the formation of lipogranulomas. Here, we can propose two hypotheses regarding the mechanism of lipogranuloma formation. One is that the vacuolated hepatocytes with brown pigments (or iron/ lipid) in their cytoplasm are phagocytized by Kupffer cells, and the other is that free pigments (or free iron/lipid in blood) are directly phagocytized by Kupffer cells. Since the pigmentation score of lipogranulomas showed positive correlation with that of both hepatocytes and sinusoidal cells, both hypotheses were thought to be possible.

Given the above, we considered that the pigments of lipogranulomas could be derived from both hepatocytes and Kupffer cells. Moreover, lipogranulomas might be a potential indicator of accumulation of iron and lipid inside the liver.

\section{Conclusion}

There was no correlation between the density of lipogranulomas and the distribution of fibrosis in the canine liver. Pigmentation of hemosiderin and ceroid in lipogranulomas had significant correlations with that in hepatocytes and in sinusoidal cells, respectively, indicating that these pigments in lipogranuloma might be derived from both hepatocytes and Kupffer cells. It is concluded that lipogranulomas are not a contributing factor for hepatic fibrosis, but a potential indicator for the accumulation of iron and lipid inside the liver.

\section{Methods}

\section{Liver samples}

The liver samples used in the present study were obtained from 52 dogs autopsied between January 2005 and December 2006 at the Department of Veterinary Pathol-

Table 3: Estimated scores of pigmentation of lipogranulomas, hepatocytes and sinusoidal cells.

\begin{tabular}{lcc}
\hline & Berlin blue & Schmorl \\
\hline Lipogranulomas & $2.2 \pm 1.1^{\mathrm{a}}$ & $2.2 \pm 0.7^{\mathrm{a}}$ \\
Hepatocytes & $1.3 \pm 0.9^{\mathrm{b}}$ & $2.1 \pm 0.6^{\mathrm{c}}$ \\
Sinusoidal cells & $2.3 \pm 1 . \mathrm{I}^{\mathrm{c}}$ & $2.1 \pm 0.8^{\mathrm{c}}$ \\
\hline
\end{tabular}

Score $=$ Mean \pm S.D. Within a column, values with different superscript letters differ $(P<0.05)$. ogy, the University of Tokyo. The dogs comprised 25 males and 27 females ranging from newborn to 14 years old (Table 1).

\section{Histopathological methods}

Excised liver tissues were fixed in $10 \%$ neutral-buffered formalin, embedded in paraffin, and sectioned at $4 \mu \mathrm{m}$. The paraffin sections were stained with hematoxylin and eosin (HE). For further histopathological examination, Berlin blue stain, Schmorl reaction, and immunostains were performed.

For immunostain, deparaffinized sections were autoclaved or digested in 1\% trypsin for antigen retrieval, and then immersed in $0.3 \%$ hydrogen peroxidase to block internal peroxidase activity, and in $8 \%$ skimmed milk to block non-specific binding of the primary antibody. The primary antibodies used were: anti-rat collagen type I, rabbit serum (LSL CO., Cosmo Bio, Tokyo, Japan), diluted 1:400; and anti-mouse collagen type III, rabbit serum (LSL CO., Cosmo Bio), diluted 1:200. The sections were then reacted with each biotinylated secondary antibody (KPL, Gaithersburg, MD, U.S.A.), incubated with peroxidaselabeled streptavidin (Dako, Glostrup, Denmark), and visualized with 3,3'-diaminobenzidine-tetrahydrochloride $(\mathrm{DAB})$ as chromogen. Counterstaining was done with methyl green.

\section{Examination of liver sections}

Fibrosis in the liver was evaluated using anti-rat collagen type I and anti-mouse collagen type III antibodies. Pigmentation on lipogranulomas, hepatocytes and sinusoidal cells was also evaluated using Berlin blue-stain or the Schmorl reaction sections. Lipogranuloma density was herein determined by counting the number of lipogranulomas in 5 images $(3,200 \times 2,560$ pixels $)$, taken from each HE section with $\mathrm{a} \times 10$ objective lens. The total number of lipogranulomas in the 5 images was considered the lipogranuloma density per a defined area unit. The density of lipogranulomas was classified into 4 scores, 0 to 3 ; score 0 : total number of lipogranulomas was zero; score 1 : below ten; score 2: below twenty; and score 3: twenty-one and above.

Scoring criteria to determine the distribution of collagen type I/III in the liver are shown in Table 2. Accumulation 


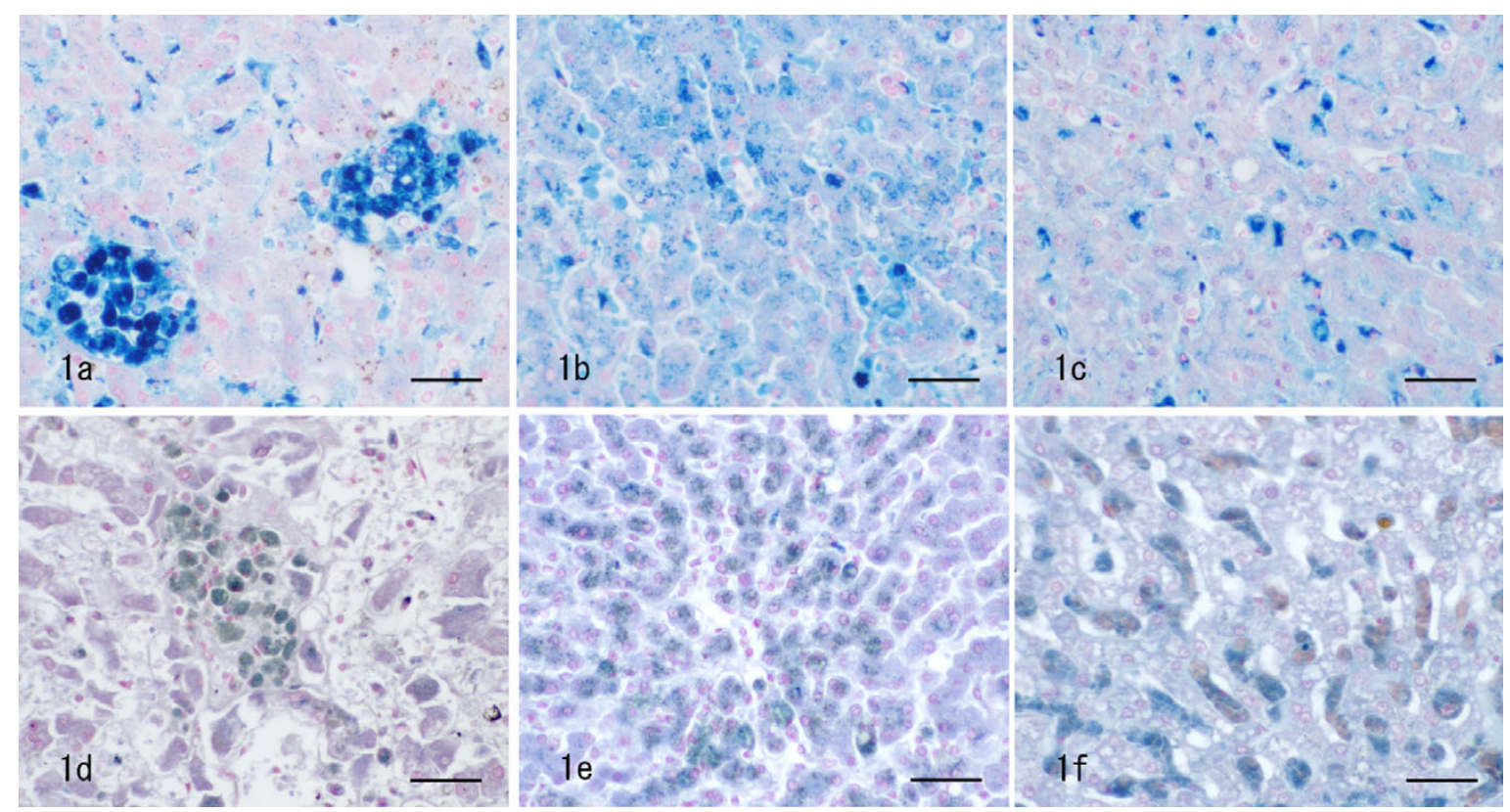

Figure I

Pigmentation in lipogranulomas, hepatocytes and sinusoidal cells. Brown pigments are positive for Berlin blue inside lipogranulomas (a), hepatocytes (b) and sinusoidal cells (c), and for Schmorl in lipogranulomas (d), hepatocytes (e) and sinusoidal cells (f). Bar $=20 \mu \mathrm{m}$.

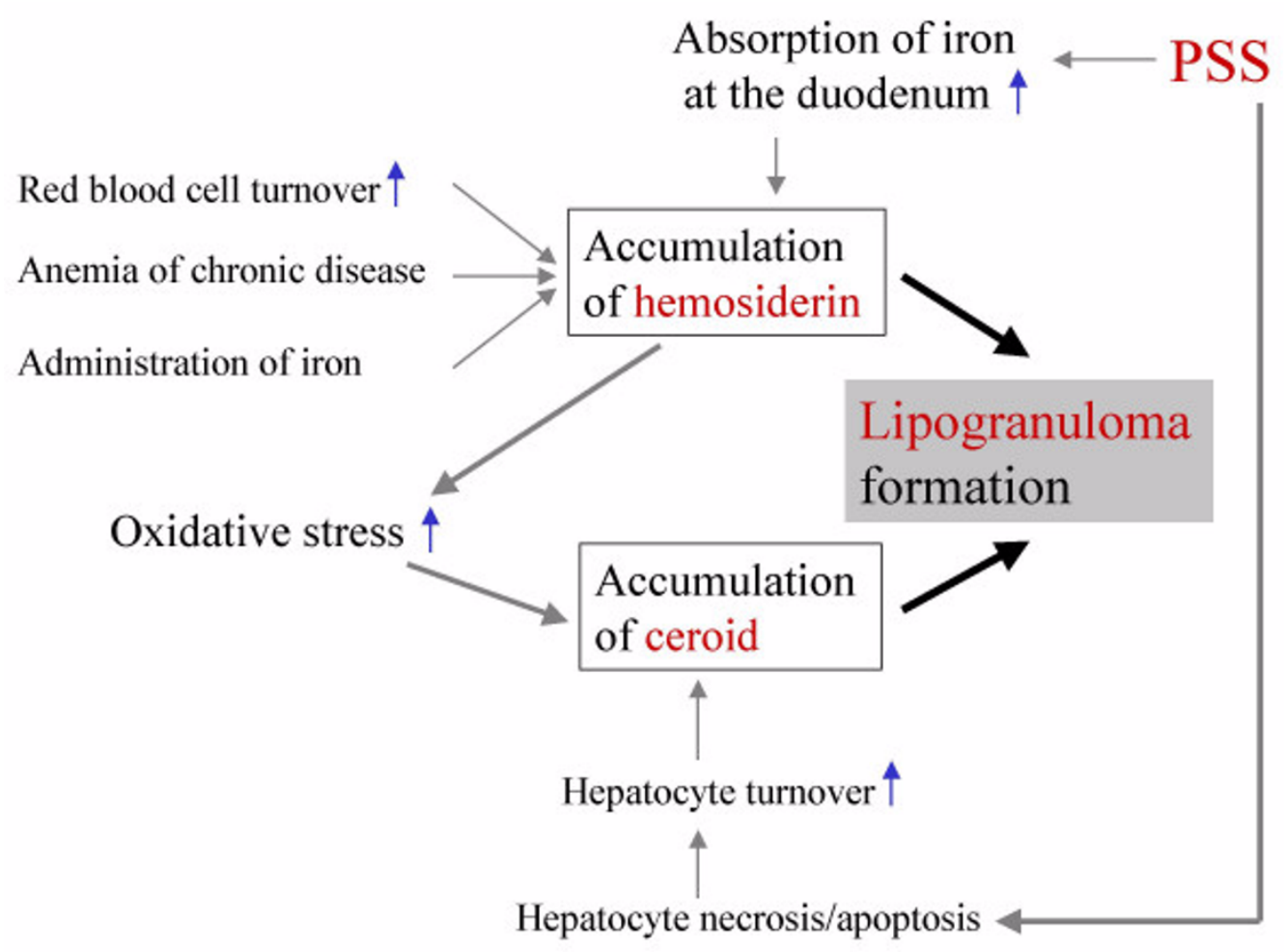

Figure 2

Mechanism diagram of lipogranuloma formation. 
of brown pigments was assessed by classifying the amount of pigments in lipogranulomas, hepatocytes and sinusoidal cells. The scoring criteria of pigmentation are also shown in Table 2.

\section{Statistical methods}

Spearman rank correlation coefficients were used to test the association between the density of lipogranuloma and distribution of collagen type I/III, and to investigate the origin of brown pigments of lipogranulomas [24]. P values less than 0.05 were considered to indicate significant differences.

\section{Competing interests}

The authors declare that they have no competing interests.

\section{Authors' contributions}

KI performed most of the experiments and prepared the manuscript. HN and KU provided assistance for the preparation of the manuscript. KU participated in the design of the study. All authors have read and approved the content of the manuscript.

\section{References}

I. Kelly WR: The liver and biliary system. In Pathology of Domestic Animals Volume 2. 4th edition. Edited by: Jubb KV, Kennedy PC, Palmer N. San Diego: Academic Press; 1993:319-406.

2. Winkle TV, Collen JM, Ingh TSGAM van den, Charles JA, Desmet VJ: Morphological classification of parenchymal disorders of the canine and feline liver. In WSAVA Standards for Clinical and Histological Diagnosis of Canine and Feline Liver Disease Ist edition. WSAVA Liver Standardization Group. Oxford: Elsevier Limited; 2006: I 03-I I6.

3. Baade S, Aupperle H, Grevel V, Schoon HA: Histopathological and immunohistochemical investigations of hepatic lesions associated with congenital portosystemic shunt in dogs. J Comp Pathol 2006, 134:88-90.

4. Borrows CF: Liver disorders. In Clinical Medicine of the Dog and Cat Ist edition. Edited by: Schaer M. London: Veterinary Press; 2003:337-349.

5. Meyer DJ: Hepatic pathology. In Strombeck's Small Animal Gastroenterology 3rd edition. Edited by: Guilford WG, Center SA, Strombeck DR, Williams DA, Meyer DJ. Philadelphia: W B Saunders; 1996:633-653.

6. Meyer DJ, Harvey JW: Hematologic changes associated with serum and hepatic iron alterations in dogs with congenital portosystemic vascular anomalies. J Vet Intern Med 1994, 8:55-56.

7. Christoffersen P, Braendstrup O, Juhl E, Poulsen H: Lipogranulomas in human biopsies with fatty change. A morphological, biochemical and clinical investigation. Acta Pathol Microbiol Scand $[A]$ 197I, 79:150-158.

8. Delladetsima JK, Horn T, Poulsen H: Portal tract lipogranulomas in liver biopsies. Liver 1987, 7:9-17.

9. Hartroft WS: Accumulation of fat in liver cells and in lipodiastaemata preceding experimental dietary cirrhosis. Anat Rec 1950, 106:61-87.

10. Hartroft WS: Diagnostic significance of fatty cysts in cirrhosis. AMA Arch Pathol 1953, 55:63-69.

II. Isobe K, Matsunaga S, Nakayama H, Uetsuka K: Histopathological characteristics of hepatic lipogranulomas with portosystemic shunt in dogs. J Vet Med Sci 70:133-138.

12. De Bleser PJ, Niki T, Rogiers V, Geerts A: Transforming growth factor-beta gene expression in normal and fibrotic rat liver. J Hepatol 1997, 26:886-893.

13. Sanderson N, Factor V, Nagy P, Kopp J, Kondaiah P, Wakefield L, Roberts $A B$, Sporn MB, Thorgeirsson SS: Hepatic expression of mature transforming growth factor beta $I$ in transgenic mice results in multiple tissue lesions. Proc Natl Acad Sci USA 1995, 92:2572-2576.

14. Xidakis C, Ljumovic D, Manousou P, Notas G, Valatas V, Kolios G, Kouroumalis E: Production of pro- and anti-fibrotic agents by rat Kupffer cells; the effect of octreotide. Dig Dis Sci 2005, 50:935-94I.

15. Lupher ML, Gallatin WM: Regulation of fibrosis by the immune system. Adv Immunol 2006, 89:245-288.

16. Hata J, Ikeda E, Uno H, Asano S: Expression of hepatocyte growth factor mRNA in rat liver cirrhosis induced by $\mathbf{N}$ nitrosodimethylamine as evidenced by in situ RT-PCR. J Histochem Cytochem 2002, 50:1461-1468.

17. Akita K, Okuno M, Enya M, Imai S, Moriwaki H, Kawada N, Suzuki Y, Kojima S: Impaired liver regeneration in mice by lipopolysaccharide via TNF-alpha/kallikrein-mediated activation of latent TGF-beta. Gastroenterology 2002, 1 23:352-364.

18. Luckey SW, Petersen DR: Activation of Kupffer cells during the course of carbon tetrachloride-induced liver injury and fibrosis in rats. Exp Mol Pathol 200I, 7 I:226-240.

19. Valatas V, Kolios G, Manousou P, Xidakis C, Notas G, Ljumovic D, Kouroumalis EA: Secretion of inflammatory mediators by isolated rat Kupffer cells: the effect of octreotide. Regul Pept 2004, 120:215-225.

20. Bonkovsky HL, Lambrecht RW, Shan Y: Iron as a co-morbid factor in nonhemochromatotic liver disease. Alcohol 2003, 30:137-144.

21. Terman A, Brunk UT: Lipofuscin. Int J Biochem Cell Biol 2004, 36: $1400-1404$.

22. Doberneck RC, Fischer R, Smith D: Gastrojejunostomy inhibits postshunt siderosis. Surgery 1975, 78:334-338.

23. Seehafer SS, Pearce DA: You say lipofuscin, we say ceroid: defining autofluorescent storage material. Neurobiol Aging 2006, 27:576-588

24. Speeti M, Ståhls A, Meri S, Westermarck E: Upregulation of major histocompatibility complex class II antigens in hepatocytes in Doberman hepatitis. Vet Immunol Immunopathol 2003, 96: I- I2.

Publish with Bio Med Central and every scientist can read your work free of charge

"BioMed Central will be the most significant development for disseminating the results of biomedical research in our lifetime. "

Sir Paul Nurse, Cancer Research UK

Your research papers will be:

- available free of charge to the entire biomedical community

- peer reviewed and published immediately upon acceptance

- cited in PubMed and archived on PubMed Central

- yours - you keep the copyright

Submit your manuscript here:

http://www.biomedcentral.com/info/publishing_adv.asp
BioMedcentral 